\title{
Anthropometric and Somatotype Characteristics of Emigrant Canadian Women Living in Canada
}

\author{
Anup Adhikari \\ Anthropometrica, Toronto, Ontario, Canada \\ Email address: \\ dranupadhikari@yahoo.com \\ To cite this article: \\ Anup Adhikari. Anthropometric and Somatotype Characteristics of Emigrant Canadian Women Living in Canada. American Journal of \\ Sports Science. Special Issue: Kinanthropometry. Vol. 4, No. 1-1, 2016, pp. 22-26. doi: 10.11648/j.ajss.s.2016040101.14
}

\begin{abstract}
One thousand four hundred and ten (1410) adult women age ranged from 19 to 40 year were measured randomly for their anthropometric and somatotype characteristics as a part of fitness counselling at local fitness clubs during the year 2010-2012 at Toronto. Women were from Greater Toronto Area (GTA) of Canada and living in Canada for the last 15 years or more after migrating from different countries and were from different ethnical groups. The age ranged from 19 to 40 years with an average value of 26.2 year $( \pm 5.5)$. Observed average height for the studied women was $162.7 \mathrm{~cm}( \pm 6.9)$ with an average body mass of $68.9 \mathrm{Kg}( \pm 16.6)$. Height ranged from $151.5 \mathrm{~cm}$ to 177.5 whereas body mass ranged from $48.2 \mathrm{~kg}$ to $87.5 \mathrm{~kg}$ indicating wide range of height and body mass. Mesomorphic Endomorph body type $(6.1 \pm 2.5-4.3 \pm 1.6-1.4 \pm 1.3)$ was obtained in average. Most of them (65.9\%) were with Mesomorphic Endomorph body type whereas 10.6\% women were Endomorph-Mesomorph, rest were in different other categories. 30.8\% body fat in average was observed which was very high considering $18-20 \%$ fat range for athletic women.
\end{abstract}

Keywords: Canadian Women, Somatotype, Fat\%, Emigrant

\section{Introduction}

The somatotype is the morphological characteristic of the body built which is a phenotypic entity capable of changes with ageing, growth, exercise and nutrition. It is a convenient short hand descriptor of physique in terms of body shape and size [1].It is defined as the quantification of the present shape and composition of the human body and expressed in a three -number rating components representing endomorphy, mesomorphy and ectomorphy respectively, always in same order. Endomorphy is the relative fatness, mesomorphy is the relative musculo - skeletal magnitude, and ectomorphy is the relative linearity or thinness of the physique [2]. It is important to recognize the somatotype as a description of the body in general, and does not answer more specific questions related to the specific dimensions of the body [1].

In Canada, obesity is a public health challenge and growing concern for the past few years [3, 4, 5, 6, 7]. According to the information reveled from the joint report of Public health Agency of Canada and the Canadian Institute for Health Information [8], the number of obese adults in Canada had been increased tremendously since 1978 and doubled in the 2008 from $13.8 \%$ to $25.4 \%$ for adults over 18 years and more. Different studies also revealed that nearly $23 \%$ of Canadian population aged 18 or more were suffering from obesity with an additional $36 \%$ overweight in the year 2004 [4, 9, 10]. Thus identification of physique by somatotyping has an immense role in identifying national body type and size in terms of relative fattiness, muscularity and thinness. There were few studies on Canadian women for their somatotype rating. The last somatotype study on Canadian women was done from 1976-1978 by Bailey et al [11] and later on by Katzmarzyk et al from 1978-1981 [12]. Later on most of the studies were on athletic population [13, 14]. No study was done on somatotypic characteristics of Canadian women, especially on those who were living in Canada after migrating to Canada from other countries. Thus, the aim of the present study was to evaluate the somatotypic characteristics of Canadian women who had been migrated and living in Canada more than 15 years.

\section{Method}

\subsection{Subjects}

Participants were the healthy women from Greater Toronto Area (GTA) of Ontario province of Canada who came to the 
local fitness club for enrolling their name in fitness program and first time enrolling themselves in a fitness program. A total of 1410 women were measured on the very first day prior to their exercise program starts and study was carried out for two years from 2010-2012. Participants were the Canadian who immigrated to Canada from different countries and living in Canada for the past 15 years or more. The group was thus a combination of different ethnical groups from different countries. Age was noted according to their declaration. Race, ethnicity and duration of migration period were self reported. All the participants had participated in the study voluntarily and written consent was taken before the measurements according to club's enrollment rules, regulations and ethical issues.

\subsection{Anthropometric Measurements}

Anthropometric measurements were done on same day for every participant in same session to avoid technical error of measurement. Measurements were done by a Level4 criterion Anthropometrist accredited by International Society for the Advancement of Kinanthropometry (ISAK) [15]. Technical Error of Measurement (TEM) was followed to avoid the measurement error. Subject consents were taken before the measurements to follow the ethical issues. Methods described in the ISAK manual [16] were followed. Stature was measured with an Anthropometric rod up to $1 \mathrm{~mm}$ and body mass was measured with a digital weighing scale. Skinfold thicknesses were measured with an Harpenden skinfold caliper (Betty Int., UK and CESCORF, Brazil), Anthropometric tape and sliding caliper (CESCORF, Brazil) were used to measure circumferences and bone diameters respectively.

\subsection{Somatotype}

Heath - Carter [17] method was followed for somatotype rating. The following equations were uses for calculating somatotype.

Endomorphy $=-0.7182+0.1451 \times \Sigma \mathrm{SF}-0.00068 \times$ $\Sigma \mathrm{SF}^{2}+0.0000014 \times \Sigma \mathrm{SF}^{3}$

where $\Sigma \mathrm{SF}=$ (sum of triceps, subscapular and supraspinale skinfolds) multiplied by (170.18/height in $\mathrm{cm})$.

Mesomorphy $=0.858 \times$ humerus breadth $+0.601 \times$ femur breadth $+0.188 \times$ corrected arm girth $+0.161 \times$ corrected calf girth - height $\times 0.131+4.5$

Three different equations were used to calculate ectomorphy according to the height -weight ratio (HWR): If HWR is greater than or equal to 40.75 then,

Ectomorphy $=0.732 \times \mathrm{HWR}-28.58$

If HWR is less than 40.75 and greater than 38.25 then,

Ectomorphy $=0.463 \times \mathrm{HWR}-17.63$

If HWR is equal to or less than 38.25 then,

Ectomorphy $=0.1$

\subsection{Body Fat\%}

Durnin and Womersley [18] technique was followed for body density. Body fat $\%$ was derived from the equation of Brozek et al [19].

\subsection{Statistical Analysis}

The Statistical Package for Social Sciences (SPSS v14.0) was used for all descriptive statistics. The results are noted as means and standard deviation.

\section{Result}

Table 1 showed the Physical characteristics, somatotype components and body composition of the Canadian women in average. The age ranged from 19 to 40 years. A high average fat $\%$ was observed for the Canadian women with a range of $14.2-47.4$ percent fat.

Table 1. Physical Characteristics, Somatotype components and body fat $\%$ of the Canadian women $(n=1410)$.

\begin{tabular}{llllllll}
\hline & Age (yr) & Ht (cm) & Wt (kg) & Endo & Meso & Ecto & Fat\% \\
\hline mean & 26.2 & 162.3 & 66.9 & 6.0 & 4.2 & 1.4 & 30.7 \\
SD & \pm 5.5 & \pm 6.4 & \pm 13.7 & \pm 2.4 & \pm 1.5 & \pm 1.3 & \pm 7.2 \\
$\min$ & 19 & 151.5 & 48.2 & 1.5 & 1.6 & 0.1 & 14.2 \\
$\max$ & 40 & 177.5 & 125 & 12.2 & 8.1 & 5.4 & 47.4 \\
\hline
\end{tabular}

Table 2. Physical characteristics, Somatotype components and body fat \% of the Canadian women at different age categories.

\begin{tabular}{|c|c|c|c|c|c|c|c|}
\hline Age categories & Number & Height (cm) & Weight (kg) & Endo morphy & Meso morphy & Ecto morphy & Fat $\%$ \\
\hline Below 20 & 180 & $168.0 \pm 10.6$ & $63.8 \pm 4.6$ & $5.0 \pm 2.6$ & $3.3 \pm 2.1$ & $2.5 \pm 2.0$ & $26.7 \pm 8.3$ \\
\hline $20-29$ yrs & 1020 & $161.7 \pm 6.3$ & $66.0 \pm 14.7$ & $5.8 \pm 2.2$ & $4.1 \pm 1.5$ & $1.5 \pm 1.3$ & $30.2 \pm 6.7$ \\
\hline $30-40$ yrs & 210 & $164.7 \pm 3.8$ & $72.3 \pm 9.8$ & $7.1 \pm 2.8$ & $4.6 \pm 1.5$ & $1.1 \pm 1.4$ & $35.0 \pm 4.4$ \\
\hline
\end{tabular}

Table 2 represented the physical characteristics and body composition of the Canadian women at different age categories. Older Canadian women were more endomorphic as well as more mesomorphic than their younger counterparts which was also reflected in increased fat $\%$ as women became older.

Table 3 showed the Canadian woman's somatotype categories age wise. Most of the Canadian women were mesomorphic endomorph in all age categories. But percentage of mesomorphic endomorph was higher in 30-40 age group than other age groups.
Table 3. Percent of Canadian women in Somatotype categories.

\begin{tabular}{lllll}
\hline \multirow{2}{*}{ Somatotype category } & \multicolumn{4}{l}{ Age category } \\
\cline { 2 - 5 } & $\mathbf{1 9 - 4 0}$ & $<\mathbf{2 0}$ & $\mathbf{2 0 - 2 9}$ & $\mathbf{3 0 - 4 0}$ \\
\hline Ectomorphic Endomorph & $4.3 \%$ & $16.7 \%$ & $2.7 \%$ & 14.3 \\
Endomorphic Mesomorph & $4.3 \%$ & & $5.4 \%$ & \\
Endomorphic Ectomorph & $4.3 \%$ & $16.7 \%$ & $5.4 \%$ & \\
Mesomorphic Ectomorph & $2.1 \%$ & $16.6 \%$ & & \\
Mesomorphic Endomorph & $65.9 \%$ & $50.0 \%$ & $64.9 \%$ & $71.4 \%$ \\
Balanced & $4.3 \%$ & & $2.7 \%$ & $14.3 \%$ \\
Endomorph Mesomorph & $10.6 \%$ & & $13.5 \%$ & \\
Endomorph Ectomorph & $2.1 \%$ & & $2.7 \%$ & \\
Mesomorph Ectomorph & $2.1 \%$ & & $2.7 \%$ & \\
\hline
\end{tabular}


Fig 1, 2, 3 and 4 showed the Canadian woman's somatotype categories diagrammatically. Fig 5, 6 represented the Somatochart for the Canadian women at different ages.

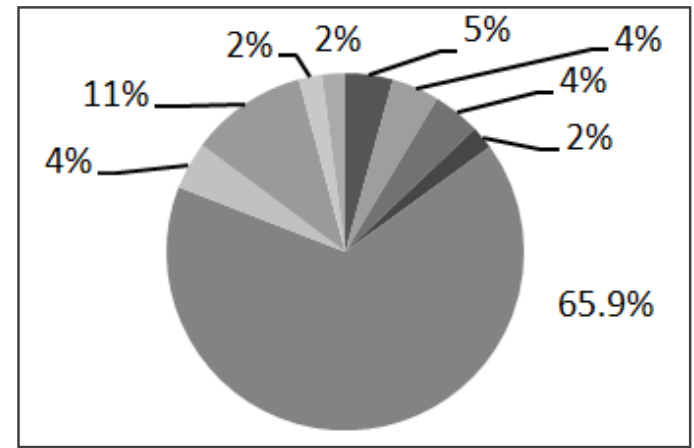

Fig. 1. Percent of Canadian women in Somatotype categories (for all ages).

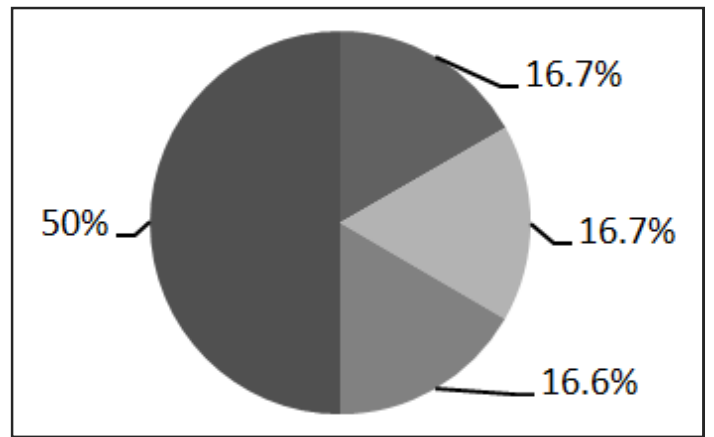

Fig. 2. Percent of Canadian women in Somatotype categories (below 20 years age category).

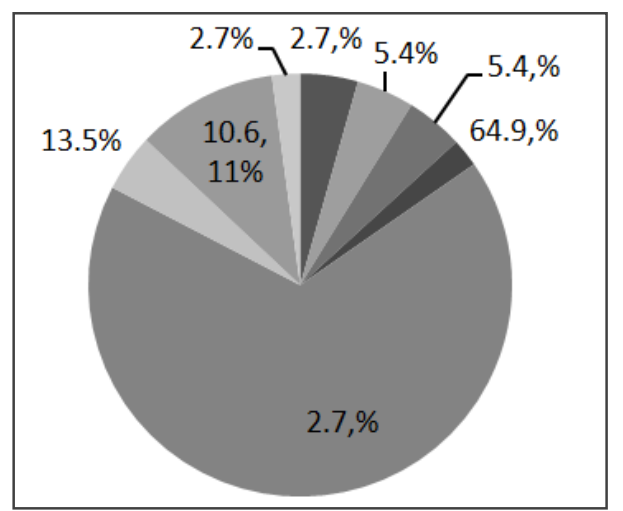

Fig. 3. Percent of Canadian women in Somatotype categories (age range 20$29 \mathrm{yr}$ ).

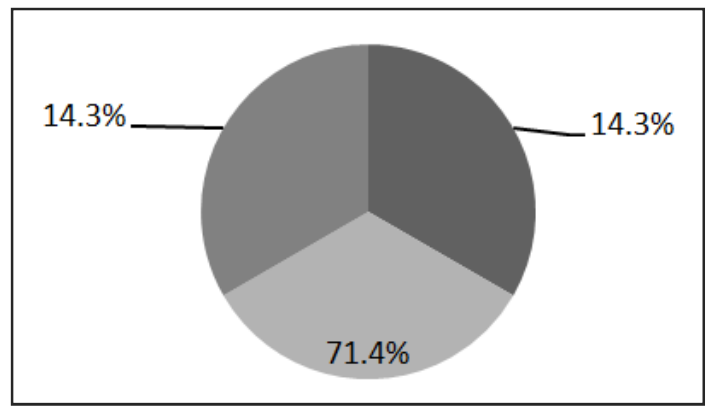

Fig. 4. Percent of Canadian women in Somatotype categories (age range 30$40 \mathrm{yr})$.

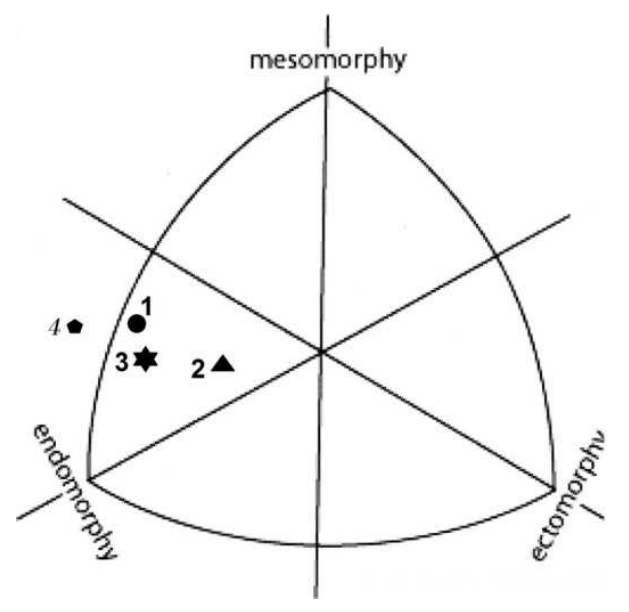

Fig. 5. Mean somatotype of female Canadian (Present study) according to age groups. Average (1), below 20yrs (2), 20-29 yrs (3), 30-40 yr(4).

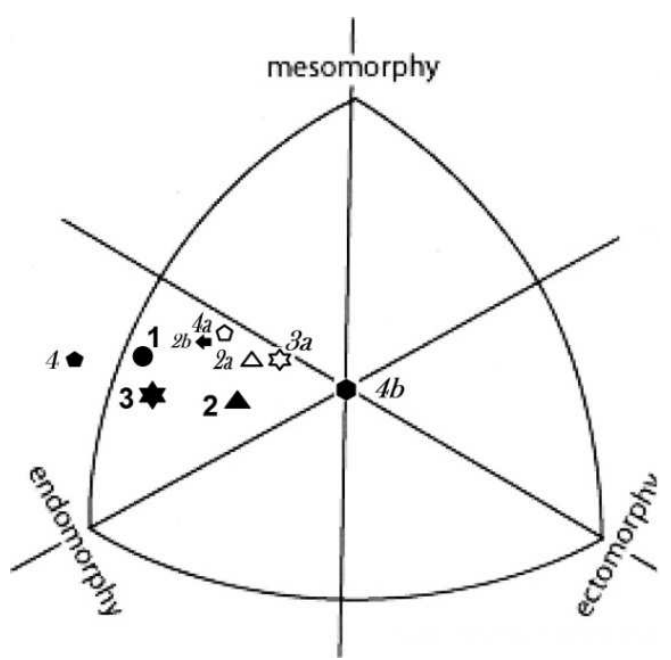

Fig. 6. Mean somatotype of Canadian women from of different studies.

1,2,3, 4 Present study ( 1 average, 2 below 20 yrs, $320 \mathrm{yr}-29 \mathrm{yr}, 430 \mathrm{yr}-40 \mathrm{yrs}$ ) 2a,3a.4a Baileyet al, (2a 15-19yrs, 3a 20-29yrs, 4a 30-39yr) $2 b, 4 b$ Katzmarzyk et al (2b 30-49 yr, 4b 9-18 yrs)

\section{Discussion}

There were very few studies on Canadian women for their somatotype characteristics. Most of the studies were done on athletic population, only very few studies were on Canadian non athletic population $[11,12]$. Bailey et al in 1982 studied on Canadian women across Canada for their somatotype characteristics [11] but other researchers also worked on somatotype characteristics while working on obesity [12]. Hence, attempts were made to compare the present study with other studies on Canadian women as well as with other similar studies on different populations.

In the present study, subjects were selected from those who were originally from other countries but migrated to Canada as an immigrant and lived here for more than 15 years without changing their ethnical food habits but changing their life style according to Canadian life style. Physical activities were different according to their profession but life style activities were very similar which were obtained from the 
questioners at the time of enrolment at the fitness centre.

Average body type of the Canadian women, observed in the present study, was mesomorphic endomorph with $30.7 \%$ body fat. Average endomorphic component was 6.0 2.4 . Components were in between 1.6 to 8.1 which indicated a huge variation in endomorphic characteristics from lean to obese reflected in the wide range of linearity from 0.1 to 5.4. That might be due to multicultural variation of body type. Similarly, though average muscularity was $4.2 \pm 1.5$, but muscularity components also varied from lowest 1.6 to highest 8.1 indicating good and poor muscularity with a wide variance. While the fat $\%$ range was from $14.2 \%$ to $47.4 \%$, high average value indicated obesity tendency of Canadian women supporting other studies [3-8].

In the present study, endomorphy components increased similar to mesomorphy components as age increased Women below 20 years possessed an average value of $5.0 \pm 2.6$ for endomorphic components which had been increased to 7.1( \pm 2.8$)$ for the 30-40 years old category (Table 2 and Fig 5 ). While age category increased above 30 years, body fat $\%$ also increased symmetrically by $8.3 \%$ from 26.7 to 35.0 (Table 2)

In all age categories, most of the Canadian women were mesomorphic endomorph (Table 3). $65.9 \%$ of total Canadian women studied in the present study were mesomorphic endomorph whereas the percentage increased to 71.4 for the women age ranged between 30 and 40 years. Women more than 20 years but less than 29 years comprises of all somatotype categories though $64.9 \%$ were mesomorphic endomorph categories. Around $16.7 \%$ were either ectomorphic endomorph, or endomorphic mesomorph, or mesomorphic endomorph when women below 20 years were considered where rests were with mesomorphic endomorph body type (Table 3 and Fig 5).

The last reported study published on somatotype characteristics of Canadian sedentary women was of Bailey et al [11] in 1982. While comparing with the women studied by Bailey et al [11] about thirty nine (39) years ago, it was observed that the women of the present study were more endomorphic in all age group though somatotype categories were same as mesomorphic endomorph in both cases. Canadian women of the present study possessed more endomorphic components for all age groups compared to the Canadian women studied in past. Average 5.0 \pm 2.1 endomorphic component for the below 20 years Canadian women of the present study was higher than the average endomorphic components of $4.3 \pm 1.2$ for the $15-19$ yrs age Canadian women studied during the year 1976-78 [1, 11]. Similarly, average endomorphic components of $5.8 \pm 2.2$ for the 20-29 yrs Canadian women of the present study was higher than average $4.4 \pm 1.3$ endomorphic components of the same age group Canadian women of the past. The difference was more when endomorphy components of the Canadian women of 30-40 age groups of both studies were compared. Canadian women of the present study possessed an average value of $7.1 \pm 2.8$ for endomorphic component compared to $4.6 \pm 1.4$ for the Canadian women reported in past $[1,11]$. The value was also higher than the Canadian women studied by Katzmarzyk et al in from 1978-1981 [12] when age group of 30-49 yrs considered. When all the women were considered irrespective of age groups, the Canadian women of the present study were also more muscular in average than the Canadian women studied in between 1976-78 [11, 12].

\section{Conclusion}

Thus from the above study it might be concluded that the Canadian sedentary women were mesomorphic endomorph in average with higher percent of body fat. The endomorphy components increased gradually as age increased same as body fat percent. More studies were required to make a final conclusion over national body type of Canadian sedentary women.

\section{References}

[1] Carter, J. E. L. and Heath, B. H., Somatotyping Developments and applications, Cambridge University Press, Cambridge, 1990, 182-197.

[2] Norton, K., and Olds, T., Anthropometrica- A textbook of body measurement for sports and health courses, University of New South Wales Press Ltd, Sydney, Australia, 1986, 148156.

[3] Gilmore, J., Body mass index and health. Health Reports (Statistics Canada, Catalogue 82-003), 11(1): 31-43, 1999.

[4] Katzmarzyk, P. T., The Canadian obesity epidemic, 19851998, Canadian Medical Association Journal, 166(8): 10391040, 2002.

[5] Tremblay, M. S., Katzmarzyk, P. T., Willms, J. D., Temporal trends in overweight and obesity in Canada, 1981-1996, International Journal of Obesity, 26: 538-43, 2002.

[6] Tremblay, M. S., Pérez, C. E., Ardern, C. I., Bryan, S. N., Katzmarzyk, P. T., Obesity, overweight and ethnicity, Statistics Canada, Catalogue 82-003. Health Rep 16(4): 2334. 2005.

[7] Anup Adhikari, Prevalence of Obesity among Immigrants Living in Canada. American Journal of Sports Science and Medicine, vol. 2, no. 1: 35-39, 2014.

[8] Public health Agency of Canada and the Canadian Institute for Health Information, Obesity in Canada - A joint report from the Public Health Agency of Canada and The Canadian Institute for Health information. 2011, Available from www.phac-aspc.gc.ca/hp-ps/hl-mvs/oic-oac/index-eng.php.

[9] Shields, M., Tremblay, M. S., Laviolette, M., Craig, C. L., Janssen, I., Gorber, S. C., Fitness of Canadian adults: Results from the 2007-2009 Canadian Health Measures Survey, Statistics Canada, Catalogue no. 82-003-X-Health Reports, vol 21, no1, March 2010, available from www.statcan.gc.ca.

[10] Tjepkema, M., Nutrition: Findings from the Canadian Community Health Survey - Adult Obesity in Canada: Measured height and weight, Issue no. 1, Component of Statistics Canada Catalogue no. 82-620-MWE2005001, 2010. 
[11] Bailey, D. A., Carter, J. E. L., Mirward, R. L., Somatotype of Canadian men and women, Human bilology, 54(4): 813-828, 1982.

[12] Katzmarzyk, P. T., Malina, R. M., Song, T. M. K., Bouchard, C., Physique, subcutaneous fat, adipose tissue distribution, and risk factors in the QueÂ bec Family Study, International Journal of Obesity, 23: 476-484, 1999.

[13] Anup Adhikari, Edward McNeely. Anthropometric Characteristic, Somatotype and Body Composition of Canadian Female Rowers. American Journal of Sports Science. Vol. 3, No. 3, 61-66, 2015.

[14] Anup Adhikari, Jady Nugent. Anthropometric Characteristic, Body Composition and Somatotype of Canadian Female Soccer Players, American Journal of Sports Science. Special Issue: Science \& Soccer. Vol. 2, No. 6-1, 14-18, 2014.

[15] International Society for the Advancement of Kinanthropometry (ISAK), available at www.isakonline.com.
[16] ISAK, International Standards for Anthropometric Assessment, ISAK manual, International Society for the Advancement of Kinanthropometry (ISAK), Lower Hutt, New Zealand, 2011.

[17] Heath, B. H., and Carter, J. E. L., A modified somatotype method, American Journal of Physical Anthropology, 27: 5774, 1967.

[18] Durnin, J. V. G. A., Womersly, J., Body fat assessed from total body density and its estimation from skinfold thicknesses, British Journal of Nutrition, 32: 77-79, 1974.

[19] Brozek, J., Grande, F., Anderson, J. T., Keys, A., Densiometric analysis of body composition: revision of some quantitative assumption, Annals of the New York Academy of Sciences, 110: 113-140, 1963. 